\title{
Loss of electrically active myocardium during inferior infarction in $\operatorname{man}^{1}$
}

\author{
A. P. SELWYN, K. FOX, ELIZABETH WELMAN, A. JONATHAN, AND \\ J. P. SHILLINGFORD \\ From the Cardiovascular Research Unit, Royal Postgraduate Medical School, Hammersmith Hospital, \\ Du Cane Road, London
}

SUMMARY Serial 72 point praecordial electrocardiographic maps were recorded in 19 patients who suffered from uncomplicated inferior myocardial infarction. The natural history of ST segment elevation and of regional loss of $R$ waves and development of $Q$ waves were recorded. Plasma $M B$ creatine kinase activity was measured at intervals during the first four days after the onset of chest pain.

The electrocardiographic maps showed that the praecordial area of ST segment elevation reached a maximum within 1 hour then diminished rapidly and disappeared in 18 of the 19 patients within 7 days after the onset of chest pain. The regional loss of $R$ waves occurred within 6 hours from the onset of pain. The praecordial area of $Q$ waves appeared in the second hour and was fully developed within 12 hours after the onset of chest pain.

Electrocardiographic changes indicating loss of electrically active myocardium were almost complete before $\mathrm{MB}$ creatine kinase activity appeared in the plasma. The timing of electrocardiographic events in relation to the onset of symptoms and to the detection of cardiospecific enzyme activity in the blood may be important in deciding when to make therapeutic interventions and how to assess their effects on the progressive loss of active myocardium during acute infarction of the heart.

There were reciprocal and complicated electrocardiographic manifestations of posterior and/or lateral myocardial involvement in these patients. In addition the praecordial area of ST segment elevation showed rapid resolution in the 4 hours after the onset of pain. For these reasons there was no simple relation between areas of ST segment elevation, the loss of $\mathrm{R}$ wave amplitude, and the appearance of $\mathbf{Q}$ waves in these patients with inferior myocardial infarction.

It is important to understand the pattern and time course of the electrocardiographic manifestations of necrosis during acute cardiac infarction before one can assess treatments aimed at conserving viable myocardium. Recent research has shown the progressive changes in praecordial ST segment elevation, $R$ wave loss, and the development of $Q$ waves in electrocardiographic maps during uncomplicated anterior infarction (Selwyn and Shillingford, 1977; Selwyn et al., 1977).

In this investigation, the praecordial electrocardiographic manifestations of ischaemia (ST segment elevation) and cell death ( $R$ wave loss and development of $Q$ waves) were followed during acute inferior myocardial infarction. The relation

${ }^{1}$ This work was financed in part by the British Heart Foundation.

Received for publication 12 October 1977 between the onset of chest pain, the electrocardiographic abnormalities, and the appearance and disappearance of plasma MB creatine kinase activity has been studied.

\section{Methods}

PATIENTS

Nineteen patients ( 14 men and 5 women, aged from 37 to 68 years (mean 57 years)) were studied after admission to the coronary care unit at the Hammersmith Hospital with a clinical diagnosis of acute inferior myocardial infarction. All these patients developed typical serial electrocardiographic abnormalities of acute inferior myocardial infarction on the routine 12 lead electrocardiogram, had a diagnostic rise in serum enzymes, and had an uncomplicated course after admission. None developed (a) recurrent chest pain lasting more than 5 minutes 
that was separate from the initial episode, (b) clinical or chest $x$-ray evidence of congestive heart failure or pulmonary oedema, or (c) cardiac rhythm disturbances other than unifocal isolated ventricular ectopic beats.

Praecordial electrocardiographic maps were recorded on admission (when this was less than 1 hour), 1 hour after the onset of chest pain, then 4 hourly for 12 hours, and daily thereafter. Additional observations were made if the clinical condition changed. Four patients were seen within the first hour after the onset of chest pain, a further 10 presented between 1 and 4 hours, and 5 presented between 4 and 6 hours after the onset of pain. Electrocardiograms were recorded using a direct writing ink jet Mingograf (Elema-Schonander) recording on 3 channels simultaneously. The gain employed was $10 \mathrm{~mm}$ for $1 \mathrm{mV}$ and the paper speed was $25 \mathrm{~mm}$ per second. The electrodes were the Welsh suction type with a contact diameter of $1 \mathrm{~cm}$. Electrocardiograms were recorded from 72 points distributed evenly over the praecordium as described by Reid et al. (1971).

The TP segment was used as the isoelectric line, or the PQ segment when the TP segment was difficult to locate because of tachycardia. ST segment elevation was measured in millimetres to the nearest $0.5 \mathrm{~mm}$ at $0.06 \mathrm{~s}$ after the nadir of the $S$ wave. At each electrocardiographic position the $R$ and $S$ waves were measured in $\mathrm{mm}$ to the nearest $0.5 \mathrm{~mm}$ and the $R / S$ ratio was calculated. $R$ wave height alone was used when the $S$ wave measured less than $0.5 \mathrm{~mm}$. Praecordial maps were always recorded with the patients at rest and reclining at $45^{\circ}$.

The appearance of QRS widening, bundlebranch block, or pathological axis changes can alter the interpretation of these electrocardiographic signs (Massie and Walsh, 1960; Beckwith, 1970). Patients whose electrocardiograms showed QRS widening beyond $110 \mathrm{~ms}$, or axis changes beyond $-30^{\circ}$ and $+120^{\circ}$ in the frontal plane were excluded from this study. Pathological $Q$ waves were identified using the Minnesota Code criteria (Blackburn et al., 1960; Rose and Blackburn, 1968). QR waves were identified as those complexes showing pathological $\mathbf{Q}$ waves but with dominant $\mathbf{R}$ waves, and Qr waves were defined as those complexes showing $r$ waves smaller than the accompanying pathological $Q$ waves.

A test of the reproducibility of praecordial mapping has already been published (Selwyn and Shillingford, 1977; Selwyn et al., 1977). The surface maps produced in this way from patients suffering acute infarction showed areas of (1) ST segment elevation greater than $2 \mathrm{~mm}$; and (2) $\mathrm{Q}, \mathrm{Qr}$, and $\mathrm{QR}$ waves.
Praecordial maps from each patient at each time interval were used to calculate the sum of all the $Q$ waves measured in $\mathrm{mm}(\Sigma \mathrm{Q})$ and to count the number of positions showing $Q, Q R$, and $Q r$ waves in the 72 point map (area $Q$ ). Each map was also used to calculate the sum of all the ST segment elevation in $\mathrm{mm}(\Sigma S T)$ and the number of praecordial positions showing ST elevation of more than $2 \mathrm{~mm}$. The 72 electrocardiographic complexes in each praecordial map were used to calculate a mean value for $R / S$ ( $R$ wave amplitude in $\mathrm{mm}$ was used where $S$ waves were $<0.5 \mathrm{~mm}$ ).

A multiple analysis of variance was used to test the significance of changes seen in the praecordial maps. This takes into account the importance of variables resulting from non-cardiac events (e.g. respiration and posture).

Five millilitre venous blood samples (taken at 3hourly intervals for the first 24 hours after onset of chest pain, then 6 hourly for 4 days) were drawn from each patient into lithium heparin tubes and centrifuged at $2000 \mathrm{~g}$ for 10 minutes. Total plasma CK activity was measured spectrophotometrically (using Cecil 272 system spectrophotometer, Cecil Instruments, Cambridge) by the method of Oliver (1955) as modified by Hearse et al. (1973). Using this method the upper limit of plasma CK activity for healthy subjects is $50 \mathrm{mU} / \mathrm{ml}$ (Ogunro et al., 1976).

Samples with activity greater than $250 \mathrm{mU} / \mathrm{ml}$ were diluted before determination of total $\mathrm{CK}$. In order to minimise the dilution-activation effect observed with plasma $\mathrm{CK}$, heat inactivated plasma was used as diluent (Graig et al., 1967).

Isoenzymes of CK were separated by electrophoresis on agarose gel and quantified in aqueous solution by fluorometry (Ogunro et al., 1976). The plasma activity of the MB-isoenzyme of CK was plotted against the time after the onset of chest pain to show the appearance and disappearance of this cardiospecific isoenzyme in the circulation.

\section{Results}

The typical changes in the praecordial electrocardio- $N$ graphic signs of ST segment depression and eleva- N tion are shown in Fig. 1. The praecordial area and height of ST segment elevation reached a maximum within the first hour after the onset of chest pain. Both decreased significantly thereafter and disappeared in 5 patients within 8 hours. A further 6 patients lost all ST segment elevation between 8 and 24 hours, and within 7 days from the onset of chest pain 18 of the 19 patients had no significant praecordial ST segment elevation (Fig. 2). The analysis of variance showed that the changes in the prae- 


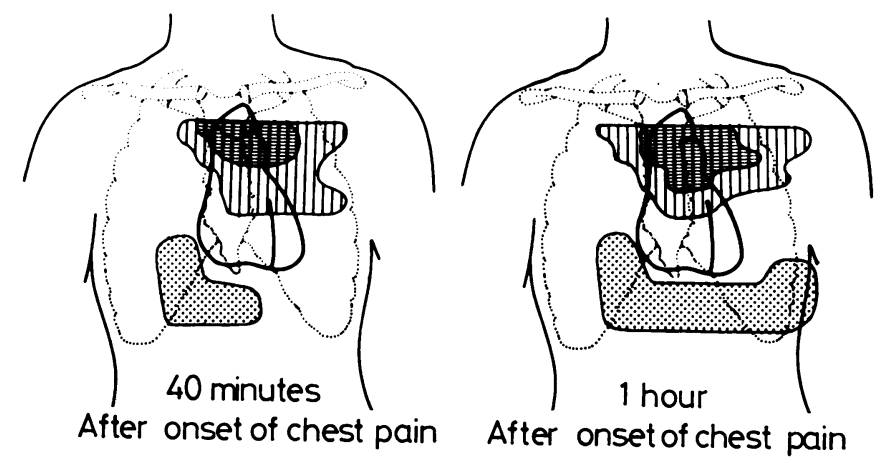

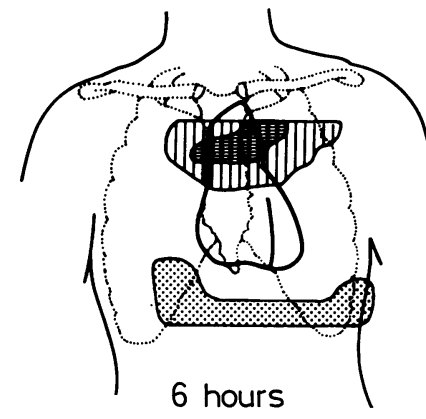

After onset of chest pain

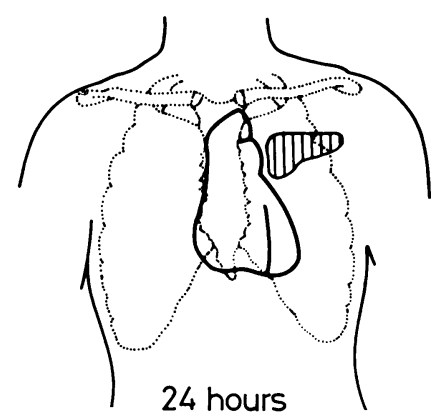

After onset of chest pain

Fig. 1 Serial praecordial electrocardiographic maps showing typical changes seen in the area of ST segment elevation outlined during acute inferior myocardial infarction.

cordial area of ST segment elevation after 1 hour from the onset of pain were highly significant $(\mathrm{P}<$ 0.001 ).

The praecordial $R / S$ showed an initial increase in $R$ wave amplitude $(n=4)$. This was followed by $a$ rapid loss of $R$ waves and a development of $Q$ waves, which were complete within 12 hours from the onset of chest pain in all 19 patients (Fig. 3). A typical example of the pattern of changes in RS ratios, $Q R$, and $Q$ waves is shown in Fig. 4. An example of the changes in RS ratio (showing increase in $R$ wave amplitude) seen in the mid and upper areas of the

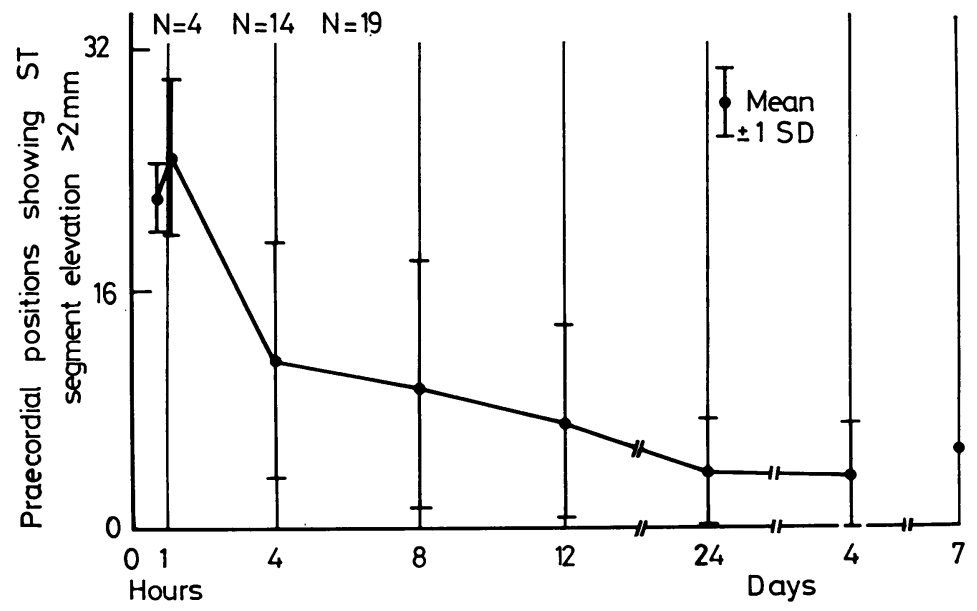

After onset of chest pain
Fig. 2 The praecordial area of $S T$ segment elevation (number of positions showing $S T$ change $>2$ $\mathrm{mm}$ ) reaches a peak within 1 hour and diminishes rapidly after the onset of chest pain. 


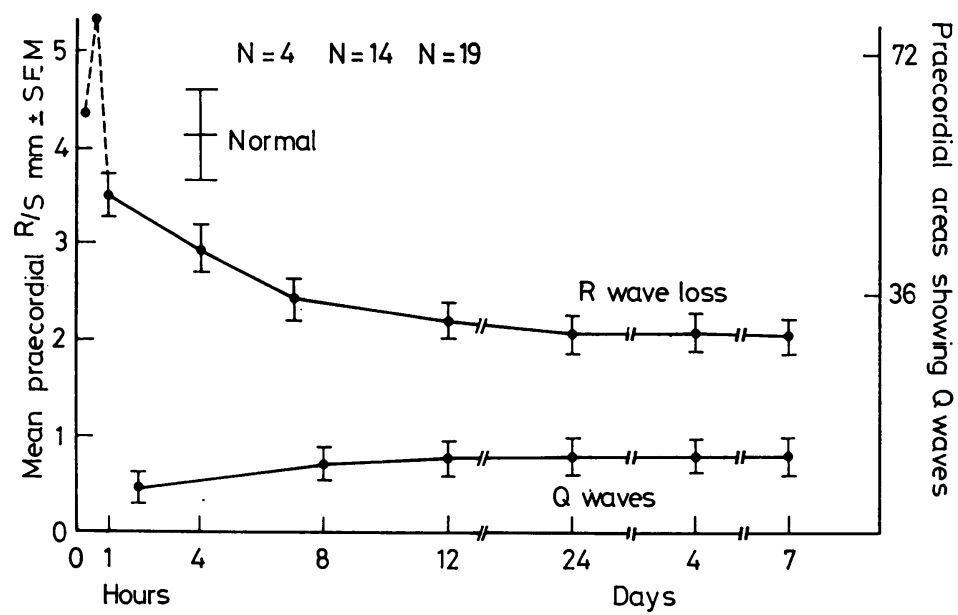

Fig. 3 The mean praecordial $R S$ ratio changes showed a progressive loss of $R$ wave after the onset of chest pain in 19 patients suffering inferior myocardial infarction. The development of the praecordial area of $Q$ waves is also shown.

After onset of chest pain

praecordial maps in 7 of these patients is shown in Fig. 5. The praecordial positions involved showed $36 \pm 4$ per cent increase in $R S$ ratio or $R$ wave amplitude. When the mean praecordial $R / S$ ratios were calculated the temporary regional increases in $\mathbf{R}$ wave amplitude were included.
In the 14 patients studied within 4 hours from the onset of chest pain the praecordial electrocardiographic positions showing ST segment elevation between 2 and $4 \mathrm{~mm}$ lost $42 \pm 27$ per cent (mean \pm $\mathrm{SD}$ ) of $\mathrm{R}$ wave amplitude and $16 \pm 3$ per cent of these positions showed pathological $\mathrm{Q}$ waves at 24
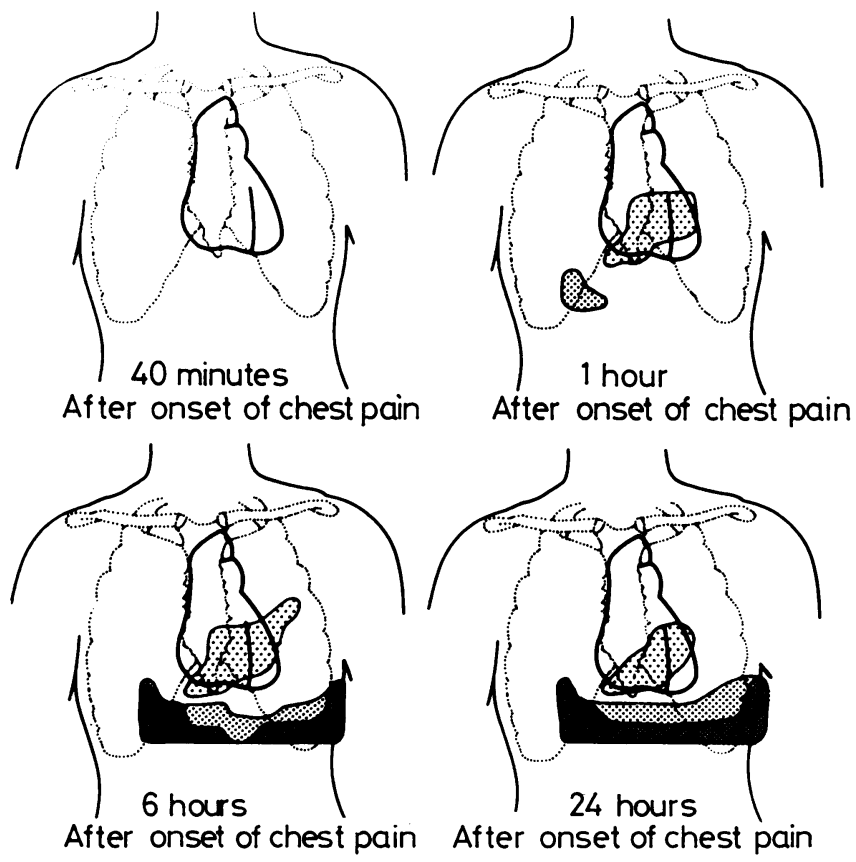

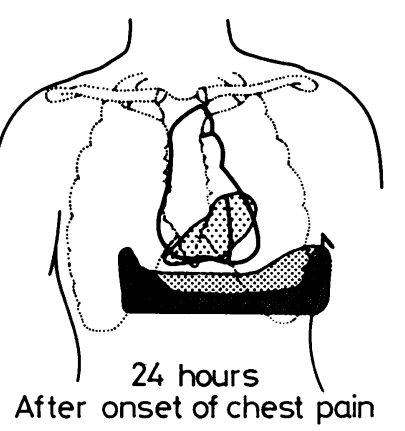

Fig. 4 A typical example of the praecordial regional loss of $R$ wave electromotive force and development of $Q$ waves during inferior myocardial infarction. An area showing reciprocal simultaneous increases in $R$ wave amplitude is shown. 


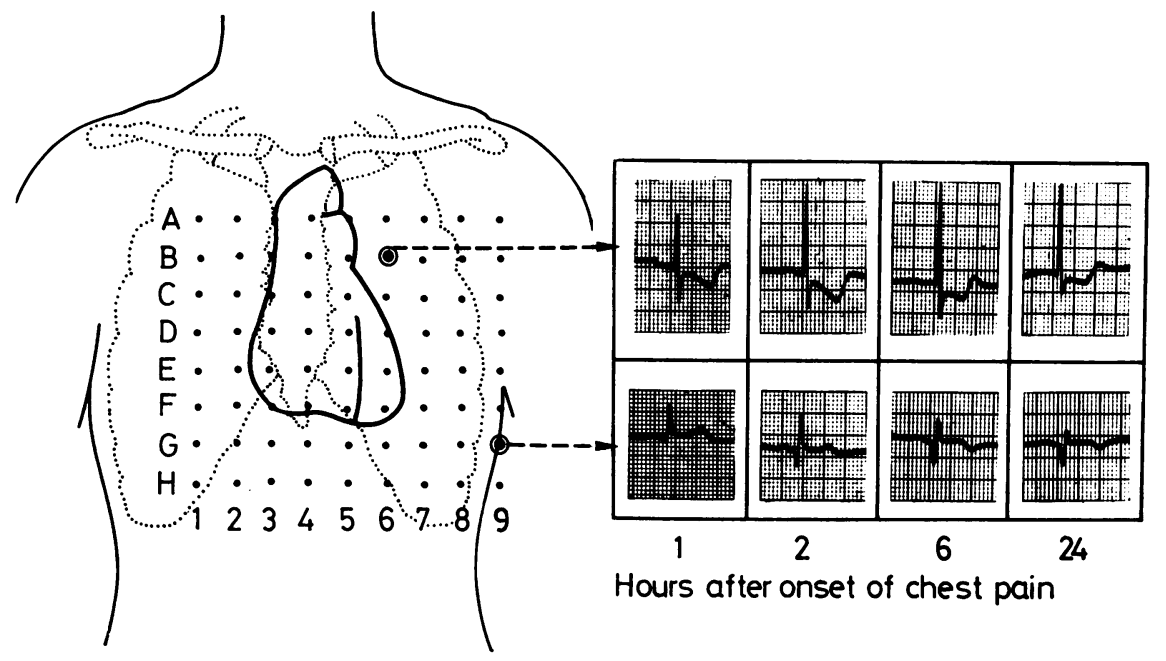

Fig. 5 Serial electrocardiograms from praecordial position $G 9$ showing the loss of $R$ and development of $Q$ waves and serial electrocardiograms from position $B 6$ show reciprocal changes after the onset of chest pain. These were not seen in the routine 12 lead electrocardiogram.

hours. The praecordial positions showing ST segment elevation of between 4 and $10 \mathrm{~mm}$ within 4 hours lost $79 \pm 24$ per cent of $R$ wave amplitude and $32 \pm 5$ per cent of these showed $Q$ waves at 24 hours. There was no relation between the early praecordial areas of ST segment elevation at 2 to 4 hours and the later areas of $R$ wave loss and/or $Q$ waves.

MB creatine kinase activity was detected in the plasma at 6 hours (median 6 hours, interquartile range 5.4 to 6.4 hours with $90 \%$ confidence limits for the median of 5.5 to 6.4 hours; $n=19$ ). Maximum MB CK activity (range $80-251 \mathrm{mU} / \mathrm{ml}$ ) was measured at 19.4 \pm 1.7 hours (mean \pm SD) and all detectable activity was cleared from the plasma by $58 \pm 5 \cdot 3$ hours after the onset of chest pain.

\section{Discussion}

This study has shown that the praecordial area of ST segment elevation reached a peak within 1 hour and then diminished rapidly and disappeared within 7 days in 18 of the 19 patients. $R$ wave loss and the development of $Q$ waves were noted in the 2 nd hour and progressed to complete development within 12 hours from the onset of chest pain. In 7 patients an area showing significant increases in $\mathbf{R}$ wave amplitude was outlined in the middle and upper portions of the praecordial maps and was accompanied by ST segment depression. This occurred during the loss of electrically active myo- cardium recorded in the lower portions of the maps and probably represented reciprocal changes in the anterior electrocardiographic forces because the posterior aspect of the heart was involved during the myocardial infarction. This electrocardiographic sign was not detectable in the routine 12 lead electrocardiogram in 4 of the 7 patients studied.

The praecordial electrocardiographic signs of inferior myocardial infarction were complicated. Praecordial ST segment elevation resolved rapidly so that within 4 hours this manifestation of ischaemia could no longer be identified at many praecordial sites that subsequently lost $R$ wave amplitude. The ST segment elevation, $R$ and $Q$ wave changes all had different natural histories. In these patients with inferior myocardial infarction characteristic ST segment elevation and changes in $\mathbf{R}$ wave amplitude were accompanied and influenced by the electrocardiographic abnormalities of posterior and/or lateral myocardial involvement. The praecordial positions showing pathological ST segment elevation $>2 \mathrm{~mm}$ did lose $\mathrm{R}$ wave amplitude and develop $Q$ waves. However, the indirect and incomplete projection of inferior infarcts was not associated with any simple relation between the early praecordial electrocardiographic manifestations of ischaemia (ST segment elevation) and the later electrocardiographic signs of cell death ( $Q$ waves).

Serial praecordial mapping of the electrocardiogram during anterior myocardial infarction can 
provide a non-invasive assessment of changes in a number of well-known electrocardiographic signs. Previous studies have shown that only tracings recording during sinus rhythm can be used and the significant effects of posture, respiration, and other abnormalities of impulse conduction must be excluded (Selwyn and Shillingford, 1977; Selwyn et al., 1977). These earlier studies showed the natural history of ST segment elevation, the regional loss of $R$ wave electromotive force, and the development of $\mathrm{Q}$ waves during anterior infarction. The regional loss of electrically active myocardium occurred before $M B C K$ activity was detected in the plasma and the praecordial area of ST segment elevation at 2 hours could reasonably predict the final area of $Q$ waves at 24 hours after the onset of chest pain in each patient. In patients suffering anterior infarction both these factors may be important and useful in deciding when to administer interventions and how to assess their effects (Selwyn and Shillingford, 1977; Selwyn et al., 1977).

In conclusion, praecordial mapping of the electrocardiogram in a group of patients suffering acute uncomplicated inferior myocardial infarction has shown that ST segment elevation is a rapidly changing electrocardiographic sign. The complex geometric factors influencing the projection of electrocardiographic signs from the heart onto the praecordium during inferior infarction invalidate the relation between a manifestation of acute regional myocardial ischaemia (praecordial area of ST segment elevation) and cell death (praecordial area of $Q$ waves) in each patient. The regional loss of electrically active myocardium and development of $Q$ waves is almost complete before $M B C K$ activity appears in the plasma, and the praecordial areas showing reciprocal increases in $\mathbf{R}$ wave amplitude suggest posterior cardiac involvement and do not always show in the routine electrocardiogram.

\section{References}

Beckwith, J. R. (1970). (Ed.) Grant's Clinical Electrocardiography, 2nd ed., p. 111. McGraw-Hill, New York.

Blackburn, H., Keys, A., Simonson, E., Rautaharju, P., and Punsar, S. (1960). The electrocardiogram in population studies: a classification system. Circulation, 21, 1160-1175.

Graig, F. A., Smith, J. C., and Foldes, F. C. (1967). Effects of dilution on the activation of creatine phosphokinase. Clinica Chimica Acta, 15, 107-111.

Hearse, D. J., Humphrey, S. M., and Chain, E. G. (1973). Abrupt reoxygenation of the anoxic potassium arrested perfused rat heart: a study of myocardial enzyme release. Fournal of Molecular and Cellular Cardiology, 5, 395-407.

Massie, E., and Walsh, J. T. (1960). Clinical Vector-Cardiography and Electrocardiography, p. 70. Yearbook Medical Publishers, Chicago.

Ogunro, E., Hearse, D. J., and Shillingford, J. P. (1976) Creatine kinase isoenzymes: their separation and quantitation. Cardiovascular Research, 11, 94-102.

Oliver, I. T. (1955). A spectrophotometric method for the determination of creatine phosphokinase and myokinase. Biochemical fournal, 61, 116-122.

Reid, D. S., Pelides, L. J., and Shillingford, J. P. (1971). Surface mapping of RS-T segment in acute myocardial infarction. British Heart fournal, 33, 370-374.

Rose, G. A., and Blackburn, H. (1968). Cardiovascular survey methods. World Health Organization. Monograph Series, No. 56.

Selwyn, A. P., Ogunro, E., and Shillingford, J. P. (1977). Natural history and evaluation of ST segment changes and MB CK release in acute myocardial infarction. British Heart fournal, 39, 988-994.

Selwyn, A. P., and Shillingford, J. P. (1977). Praecordial mapping of $Q$ waves and $R S$ ratio changes in acute myocardial infarction. Cardiovascular Research, 11, 167-171.

Requests for reprints to Dr A. P. Selwyn, Cardiovascular Research Unit, Hammersmith Hospital, Du Cane Road, London W12 0HS. 